\title{
Parkinson's disease - pathology, aetiology and diagnosis
}

\author{
Graeme JA Macphee and David A Stewart \\ Department of Medicine for the Elderly/Movement Disorders Clinic, Southern General Hospital, Victoria Infirmary, \\ Glasgow, UK
}

\begin{abstract}
Summary
Parkinson's disease is a progressive neurodegenerative condition. There is an increasing incidence and prevalence with advancing age and more cases are predicted as the population ages. Because of likely differing aetiology, genetics and pathology in individual patients, as well as confounding co-morbidities, diagnosis can be difficult even for specialists. We present an overview of the pathology, aetiology and differential diagnosis of Parkinson's disease in older people. The importance of specialist medical input in diagnosis is emphasized.
\end{abstract}

Key words: Parkinson's disease, older adults, differential diagnosis, pathology.

\section{Introduction}

Parkinson's disease (PD) is a progressive neurodegenerative disease characterized typically by motor features of tremor, rigidity and bradykinesia, due to depletion of dopaminergic nigrostriatal neurons. PD is increasingly recognized as a non-motor disorder since symptoms such as dementia, depression and falls emerge with disease progression to become dominant in the clinical picture. ${ }^{1}$ Stern et al. ${ }^{2}$ propose three phases in a new definition of PD. Phase 1 is preclinical PD, when PD-specific pathology is presumed to be present supported by imaging or putative biomarkers. Phase 2 - premotor PD - occurs when early nonmotor signs due to extra nigral pathology are present. Phase 3 - motor PD - is present when classic motor signs manifest, followed by later non-motor features due to disease progression. ${ }^{2}$ PD results in a significant decline in quality of life $^{3}$ for both patients and family ${ }^{4}$ and contributes to significant economic and institutional costs on family and society. ${ }^{2}$

Address for correspondence: GJA Macphee, Consultant/ Honorary Clinical Senior Lecturer, Department of Medicine for the Elderly/Movement Disorders Clinic, Southern General Hospital, Glasgow G51 4TF.

Email: Graeme.Macphee@ggc.scot.nhs.uk
Multidisciplinary input, particularly from PD nurse specialists, should be emphasized in optimal care management ${ }^{5,6}$ but is beyond the scope of this contribution. The MacMahon paradigm $^{6}$ incorporates four progressive but overlapping clinical management stages (diagnosis, maintenance, complex and palliative) and provides a template for good interdisciplinary practice. ${ }^{7}$

This is the first part of a two-part review and comprises an overview of pathology, aetiology and diagnosis. The second part will focus on pharmacological and surgical management and on important non-motor features.

\section{Epidemiology}

PD is uncommon before the age of 40 , but affects approximately $1 \%$ of patients over the age of 60 , with a rising prevalence thereafter to around $2 \%$ in the population over 80 years of age. ${ }^{8}$ There is a great variability in reported incidence rates, probably due to differences in diagnostic criteria and case ascertainment, with reported rates in Western countries ranging from 8.6 to 19.0 per 100,000 population. ${ }^{9}$ Rates are around 1.5 times higher in men than in women although this varies across different studies. ${ }^{10}$ Western populations, Australia and Asian countries including Korea and Singapore, have a similar prevalence. ${ }^{11-13}$ Prevalence and incidence rates in 13 African countries, however, are lower. ${ }^{14}$ There is no evidence that seasonal variation by birth date affects incidence. ${ }^{15}$

Patients with PD have a reduced life expectancy compared with the general population, with an age-adjusted hazard ratio in one United Statesbased study of 1.6 (confidence interval 1.3-2.0). ${ }^{16}$

\section{Risk factors}

Many studies have confirmed an inverse association between smoking and PD. The mechanism 
for this remains uncertain. ${ }^{17}$ Studies on the relation between coffee and tea drinking and PD have reported inconsistent results. There is some evidence for an inverse relationship with PD. ${ }^{18}$ Higher urate levels have also been shown to be associated with a reduced risk of PD, perhaps due to the anti-oxidant properties of urate. ${ }^{19}$ Factors with some evidence of increased PD risk include dairy product consumption and pesticide exposure. ${ }^{20,21}$

Because inflammation plays a role in the pathogenesis of $\mathrm{PD}$, the relationship between NSAID use and development of PD has been examined. Results are inconsistent, with studies reporting either no effect or an inverse association with PD. ${ }^{22,23}$ There is also some evidence that the use of simvastatin is associated with a reduced incidence of PD. ${ }^{24}$

There is a higher incidence of PD in firstdegree relatives of PD patients, with risk greater for siblings than for parents or children. ${ }^{25}$ Family members have a 3- to 4-fold increased risk compared with a control population. ${ }^{26}$

\section{Pathology}

\section{Neurochemistry}

Depletion of dopamine is the most important neurochemical abnormality in PD. Other neurotransmitters affected include acetylcholine, serotonin and noradrenaline, but the role of these substances in the clinical syndrome is uncertain. Eighty per cent of dopamine in the brain is found in the striatonigral complex (putamen, caudate and substantia nigra), with the main source of dopamine in the complex being the substantia nigra (SN). ${ }^{27}$ Five dopamine receptors in two 'families' have been described: the D1 group (D1 and D5) and the D2 group (D2, D3 and D4). These are variably distributed in brain areas such as striatum, cortex and limbic system.

\section{Pathophysiology of basal ganglia motor control (Figure 1)}

Disruption of normal dopaminergic output from the substantia nigra interferes with the basal ganglia motor circuit. This circuit is involved in the facilitation of both voluntary and involuntary movement. The connections within the motor circuit are complex and not fully understood. ${ }^{28}$

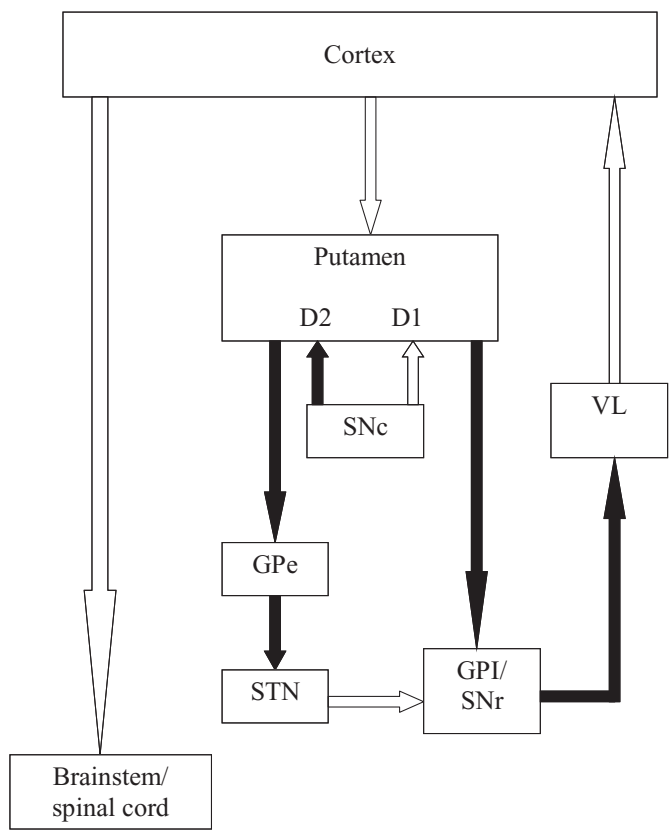

Normal

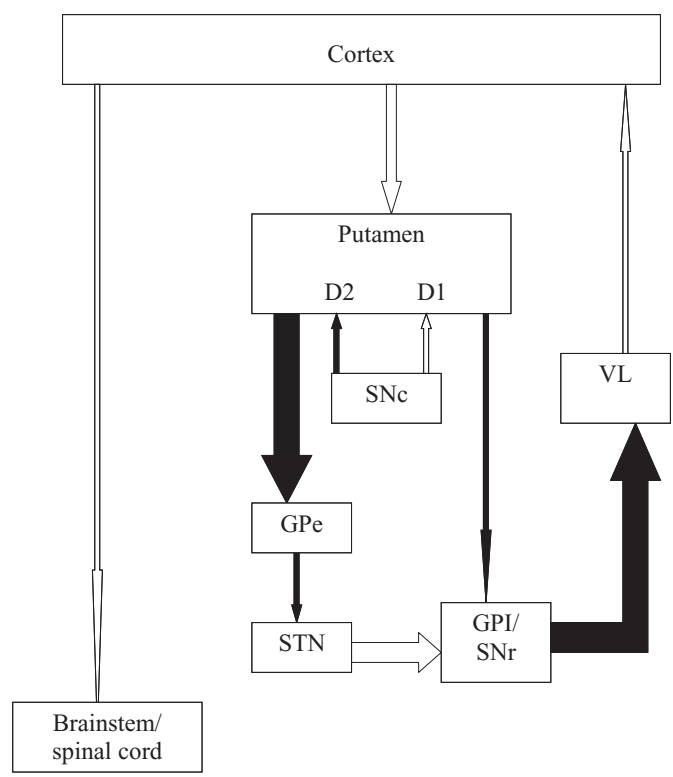

Parkinson's disease

Figure 1. Basal ganglia circuitry - normal and in Parkinson's disease. Black arrows indicate inhibitory output, and white arrows indicate excitatory output. GPe, globus pallidus externa; GPi, globus pallidus interna; STN, subthalamic nuclei; SNc, substantia nigra compacta; $\mathrm{SNr}$, substantia nigra reticulata; VL, ventrolateral thalamus. 
Striatonigral dopaminergic projections connect into the circuit via both a direct and an indirect pathway. The direct pathway involves D1 receptors and acts to reduce the inhibitory output from the globus pallidus interna (GPi), mediated by $\gamma$-aminobutyric acid (GABA). The indirect pathway involves D2 receptors. This pathway acts via the globus pallidus externa and the subthalamic nucleus, again to reduce inhibitory output from the GPi. ${ }^{29}$ In Parkinson's disease, the 'brake' on the GPi is diminished, resulting in increased inhibitory output into the thalamocortical motor circuit.

\section{Lewy bodies}

Until recently the pathological hallmark of PD was considered to be the Lewy body. Autosomal recessive forms of $\mathrm{PD}$ have been described that do not exhibit Lewy body pathology (see below), but Lewy bodies are present in the more common sporadic form of PD as well as other autosomal dominant forms. Lewy bodies are also found as the defining pathology in dementia with Lewy bodies. In addition, Lewy bodies are found variably in a number of other neurodegenerative diseases, including progressive supranuclear palsy, corticobasal degeneration and motor neurone disease. ${ }^{30}$ They are intracytoplasmic inclusion bodies consisting of an amorphous core surrounded by a less dense 'halo'. ${ }^{31}$ They contain a number of elements including ubiquitin, $\alpha$-synuclein and proteases. ${ }^{32,33}$ Their biological function is thought to involve the disposal of abnormal or damaged proteins ${ }^{34,35}$ through the ubiquitin-protease system. It remains unknown whether Lewy bodies are harmful or protective in PD. ${ }^{36}$

\section{Distribution of pathology}

The pathological changes in PD are widespread. Areas involved include thalamus, hypothalamus, limbic cortex, neocortex, locus coeruleus, raphe nucleus, nucleus basalis of Meynert and autonomic nervous system. ${ }^{31-37}$ The most important area affected is the substantia nigra pars compacta and it is damage here that is responsible for most of the clinical motor syndrome. It has been thought that cell loss in excess of $50 \%$ is required for symptoms to develop. ${ }^{38}$ This concept has recently been challenged; it has been suggested that, at symptom onset, only around $30 \%$ of dopaminergic SN neurones but $50-60 \%$ of their axons have been lost. ${ }^{39}$ The clinical correlates of pathology in other areas are poorly understood, but cholinergic deficit in the nucleus basalis of Meynert is increasingly implicated in impairments of memory and cognitive function. ${ }^{40}$

The substantia nigra pars compacta can be further subdivided into ventral and dorsal tiers. The cells of the dorsal tier are more heavily pigmented, with neuromelanin representing higher dopamine turnover. ${ }^{41}$ It is these cells that are lost preferentially in normal ageing. In contrast, the paler cells in the ventral tier are affected primarily in PD. ${ }^{42}$ This argues against PD being an exaggeration of normal ageing. There is no clear evidence that the rate of progression of pathology is influenced by age of onset of PD. ${ }^{31}$

Pathological studies have suggested that the pathology of PD may begin in the brainstem and progresses in an ascending course, towards the cortex. $^{43}$ The dorsal motor nucleus and olfactory bulb are initially involved (Braak stage 1 ), with progression thereafter through the pons and medulla (stage 2). By stages 3 and 4, the pathology has advanced to the stage where clinical symptoms emerge in response to nigro-striatal cell loss and clinical diagnosis becomes possible. By stages 5 and 6, neocortical areas are affected and this is associated with the late development of cognitive problems including dementia. ${ }^{44}$ Lewy body pathology can be more widespread than previously recognized. It can also be found in the spinal cord, the autonomic and peripheral nervous system, the skin, retina, submandibular gland, the cardiac nervous system and other organs. ${ }^{45}$

\section{Incidental Lewy body pathology}

Lewy bodies can be demonstrated at post-mortem in a distribution consistent with a pathological diagnosis of PD in subjects who had shown no evidence of the clinical syndrome in life. This is known as incidental Lewy body disease (ILBD). ILBD has been regarded as preclinical PD. ${ }^{46}$ The presence of other features, including the presence of low levels of reduced glutathione (see below), is consistent with this interpretation. The prevalence of ILBD varies from $1 \%$ in the fifth decade to $10 \%$ in the eighth decade. ${ }^{30}$ This would suggest a preclinical course of as long as 30 years. Evidence from other sources such as PET scan 
studies suggest a shorter preclinical course of 510 years. ${ }^{47}$

\section{Dementia with Lewy bodies}

Dementia with Lewy bodies (DLB) is the preferred term for the condition previously variously known as Lewy body dementia, senile dementia of Lewy body type, diffuse Lewy body disease and Lewy body variant of Alzheimer's disease. ${ }^{48}$ DLB is thought, by some, to be the second commonest form of dementia after Alzheimer's disease. ${ }^{32-49}$

Clinically, the condition is characterized by fluctuating confusion, visual hallucinations, extrapyramidal features and neuroleptic sensitivity. Pathologically, Lewy bodies are found in the cortex, but in a distribution and number overlapping that present in PD. In addition, subcortical (including substantia nigra) Lewy bodies are invariably present. It is likely that DLB lies on a continuum with PD, with the separation between the two conditions largely semantic. DLB is arbitrarily categorized as dementia predominating in the first year of symptoms. ${ }^{49}$

\section{Overlap pathologies}

Considerable pathological overlap exists between synucleinopathies (such as PD, dementia with Lewy bodies and multiple system atrophy) and tauopathies (such as Alzheimer's disease). It is thought that $\alpha$-synuclein may induce intracellular tau aggregation. ${ }^{50}$ Interaction of $\alpha$-synuclein, tau and $\beta$-amyloid may be the mechanism of overlapping pathology between Lewy body diseases and Alzheimer's disease. These diseases may represent different points on a complex continuum of pathology. ${ }^{51}$

\section{Aetiology}

\section{Genetics}

Genetic studies are hampered by the lack of a biological marker for the condition. Ascertainment of affected relatives is difficult as the disease may not become apparent until many years later. Another problem is atypical presentation of the condition; for example, isolated postural tremor has been recognized as a forme fruste of PD.
Most PD patients do not have a family history of the disease, but this can be found in $20-30 \%$ of cases. ${ }^{52}$ This figure increases to $43 \%$ if a history of isolated tremor is included..$^{53}$ In case control studies, the relative risk for a first-degree relative of an affected patient of developing PD is about $3.5 . .^{54}$

Early twin studies failed to show an increased concordance for PD in monozygotic versus dizygotic twins. This was interpreted as evidence against a significant genetic component. Identification of affected co-twins, however, depended on the presence of overt clinical disease and was therefore poorly sensitive. A study using PET scanning to detect abnormalities of dopaminergic activity has shown a concordance rate of $75 \%$ in monozygotic twins versus $22 \%$ in dizygotic twins. ${ }^{55}$

A study from Sweden, however, demonstrated very low concordance rates in twins. ${ }^{56}$ It is possible therefore, that heritability is higher for nigrostriatal dysfunction (as demonstrated by PET), but that the subsequent development of symptomatic PD depends on an environmental insult.

A complex interaction of many genes is almost certainly involved in the majority of cases of PD, but single gene defects have been identified in some cases of familial PD. These discoveries are of great potential in helping to understand the pathophysiology of the condition. In recent years genome-wide association analyses have identified a number of low-risk susceptibility variants for Parkinson's disease, notably at the SNCA, MAPT and LRRK-2 loci. ${ }^{57}$

\section{Single gene defects}

The first single gene cause for PD was found in an Italian-American family in which parkinsonism was inherited as an autosomal dominant condition. ${ }^{58}$ The disease is clinically consistent with sporadic PD, although of younger onset than is typical, and is responsive to levodopa. Lewy bodies are found at post-mortem. The cause of the syndrome in this family has been found to be a mutation of the $\alpha$-synuclein gene in chromosome $4 .^{59} \mathrm{~A}$ number of genes for Parkinson's disease have now been reported. Where known, the protein products of these genes have been showed variously to be associated with abnormal protein accumulation and degradation, 
oxidative stress and mitochondrial dysfunction. Autosomal recessive forms are usually of younger onset, slower progression and without Lewy body pathology. Parkin and PINK1 have been shown to be involved in mitochondrial quality control. ${ }^{57}$ Of the dominant forms, the recently described PARK 8 is a mutation of the LRRK-2 gene, which codes for a protein named dardarin. ${ }^{60,61}$ It most closely resembles sporadic PD in age of onset and clinical features and appears to be the most common cause of autosomal-dominant PD yet discovered, with a frequency of $1 \%$ in sporadic cases and $4 \%$ in hereditary parkinsonism. ${ }^{62,63}$

\section{Pathophysiology}

The cause of PD is unknown but research has implicated the roles of oxidative stress, mitochondrial dysfunction, inflammation and excitotoxicity as potentially important mechanisms in pathophysiology. The effects of these problems may result in cell loss through apoptosis.

\section{Oxidative stress}

The presence of iron and dopamine in the substantia nigra makes the cells vulnerable to oxidative stress. ${ }^{64,65}$ Dopamine metabolism results in the generation of toxic free radicals, a process accelerated by the presence of ferrous iron. A number of cellular defence mechanisms, including the enzymes catalase and peroxidase exist, but are thought to be impaired in PD. Of particular importance in this defence is the presence of reduced glutathione. Levels of this chemical have been shown to be low in PD. Evidence for oxidative damage in the substantia nigra in PD includes increased levels of malondialdehyde, a marker of lipid peroxidation, ${ }^{66}$ and of 8 -hydroxy2-deoxyguanosine, indicating oxidative damage of DNA. ${ }^{67}$

\section{Mitochondrial dysfunction}

Mitochondria are a vital element in cellular energy production. An important finding in PD is a deficiency of Complex 1 of the mitochondrial respiratory chain. ${ }^{65}$ This abnormality is specific to $\mathrm{PD}$ and is not found in other neurodegenerative disorders. ${ }^{64}$ Mitochondrial dysfunction may play an important role in provoking apoptotic cell death via the release of apoptotic initiating factors. Mitochondrial dysfunction can also increase oxidative stress. In addition, it has been noted that degradation of proteins by the ubiquitinproteosome system requires a series of ATPdependent peptidases. A mitochondrial respiratory chain defect will therefore impair this process. ${ }^{68}$

\section{Inflammation}

Inflammatory processes have also been implicated in the pathophysiology of PD with increased levels of inflammatory mediators (interleukins and TNF- $\alpha$ ) found. ${ }^{69}$ These stimulate the activation of microglial cells and increase nitric oxide (NO) production. This further increases oxidative stress and exacerbates cellular damage.

\section{Excitotoxicity}

Excessive glutaminergic stimulation acting on $\mathrm{N}$-methyl-D-aspartate (NMDA) receptors can damage cells via activation of a number of enzyme systems. ${ }^{70}$ Stimulation is mediated by calcium ion influx. Excessive influx is prevented by maintenance of a normal membrane potential. This, in turn, relies on mitochondrial ATP production and may be deficient in PD. Physiological levels of glutamate may therefore be toxic in PD.

\section{$\alpha$-Synuclein}

It has recently been suggested that pathology may be spread by a prion-like mechanism involving the transmission of conformationally altered $\alpha$-synuclein. ${ }^{71}$

\section{Diagnosis}

An accurate diagnosis of PD is important for determining prognosis and validating appropriate therapy, since dopaminergic therapy is commonly associated with neuropsychiatric side-effects in the elderly, particularly confusion and hallucinosis. ${ }^{72}$ A correct diagnosis also underpins therapeutic and epidemiological research. Unfortunately, there is 
as yet no robust biological marker for PD despite advancing clinical research. ${ }^{73}$

Diagnosis remains clinical, based on the core features of tremor, rigidity and bradykinesia. ${ }^{74}$ The latter feature is required for the definite diagnosis of parkinsonism, but may be difficult to distinguish from age-related slowing ${ }^{75}$ and confounders of diagnosis in the elderly such as arthritis and cerebrovascular disease.

Subtle extrapyramidal signs (EPS) are common in the elderly. EPS of variable severity were reported in $15 \%$ of community-based subjects who were $65-74$ years old, and in $52 \%$ of those over 85 years of age. ${ }^{76}$ In contrast, clinically evident parkinsonism (two or more of the cardinal motor signs) in a similar population is lower, at around $3 \% .{ }^{77}$ Parkinsonian signs may occur in association with mild cognitive impairment without evidence of overt neurological disorder, ${ }^{78}$ and may predict incident dementia. ${ }^{79}$ Parkinsonism occurring in the context of dementia becomes increasingly common in the ninth decade. ${ }^{80}$

A precise clinical definition of $\mathrm{PD}$ is not established, but is generally accepted as the presence of two or more cardinal motor signs (one of which must include bradykinesia) and a consistent response to levodopa, with the development of typical levodopa-induced dyskinesia indicative of PD. Asymmetric onset and classical pill rolling tremor are strong indicators of PD, but anomalies in symmetry and unusual patterns may occur. ${ }^{81}$

While diagnosis of PD may be straightforward, there is an extensive differential diagnosis, particularly at symptom onset. ${ }^{82}$ Clinicopathological studies suggest an error rate of approximately $25 \%$ at death, although recent studies suggest an improvement to around $10 \% .{ }^{83}$ However, specialists often require to revise their diagnosis during clinical follow-up, with an $8 \%$ revision rate reported in the large DATATOP study. ${ }^{84}$ There is a larger error rate in the community, with one study in general practice reporting that nearly $25 \%$ of patients labelled as PD have no evidence of parkinsonism. ${ }^{85}$ One in 20 patients in a recent community study in the west of Scotland was misdiagnosed. ${ }^{86}$

Population-based studies have demonstrated that $15 \%$ of patients carrying a PD diagnosis do not fulfil strict clinical criteria, and that a further $20 \%$ of patients under clinical care have not been detected. ${ }^{87}$ Early referral to specialist centres for diagnosis is therefore mandatory for optimal clinical care. ${ }^{88,89}$

The most common misdiagnoses in autopsy studies are degenerative parkinsonisms such as progressive supranuclear palsy (PSP), multisystem atrophy (MSA) or corticobasal degeneration. ${ }^{90}$ Clinical features or 'red flags' suggesting alternate diagnoses include a poor response to levodopa, early falls (PSP) or co-existent dementia (dementia with Lewy bodies or Alzheimer's disease), significant or early autonomic dysfunction such as orthostatic hypotension or urinary dysfunction (MSA), abnormal eye movements (PSP), and atypical tremor with predominant gait disorder and vascular risk factors (vascular parkinsonism). ${ }^{91} \mathrm{~A}$ large European study has emphasized that some forms of parkinsonism may be unclassifiable ${ }^{92}$ and there is increasing recognition of the expanding phenotype of many parkinsonian disorders. Recently, two distinct phenotypes of PSP have been described. ${ }^{93}$ The first phenotype, occurring in around two-thirds of cases, is akin to classical PSP (early falls, supranuclear palsy and cognitive dysfunction), now called Richardson syndrome; but a second group (PSP-P) demonstrated longer survival and older age at death and were characterized by asymmetric onset, tremor and initial response to levodopa. These patients were often misdiagnosed as PD.

Clinical studies usually highlight essential tremor, vascular parkinsonism and drug-induced causes as the most frequent mimics of PD, particularly in early presentation. ${ }^{74}$ The spectrum of drug-induced PD now extends beyond established causes such as typical and atypical neuroleptic drugs, to include agents such as sodium valproate, lithium, amiodarone and calcium channel blockers (cinnarizine and flunarizine). While symmetry of symptoms is usual, an asymmetric presentation, indistiguishable from idiopathic PD, is well recognized.

Essential tremor (ET) is a common mimic of PD because of the increasing prevalence with age. Estimates vary widely in the literature, with rates of $0.008-22 \%$ reported. A recent meta-analysis suggests the prevalence is between 0.7 and $2.2 \%$, rising to $4.6 \%$ in those over the age of 65 years. ${ }^{94}$ This compares with a prevalence for PD of less than $0.2 \%$ in the overall population.

The tremor of ET classically has a frequency of 6-12 Hz (faster than the 4-8 Hz tremor typically seen in PD), and is usually postural in nature, 
i.e. occurs when the limb is held in a fixed position against gravity, or kinetic in nature, i.e. during writing or pouring liquids. ${ }^{95}$ The frequency of the tremor is inversely related to age, ${ }^{96}$ becoming slower in older patients and thus more into the 'parkinsonian' range. Tremor usually starts in the arms but spreads to involve the head/neck in 34$53 \%$ of cases. ${ }^{97-100}$ Isolated head tremor is rare $(1-10 \%)$ and points to other diagnoses ${ }^{100}$ such as dystonic tremor. Cogwheeling may be felt whilst testing tone but there is no true rigidity, nor is there bradykinesia.

Duration of symptoms in ET will typically be longer than that of 'new' PD, and family history and exacerbating or relieving factors are important to elucidate. Many patients report a significant improvement in tremor with modest alcohol intake.

Tremor disorders with extrapyramidal signs insufficient to diagnose an established neurogenerative disorder may have to be labelled as 'indeterminate tremor syndrome' ${ }^{101}$ Difficulties occur particularly in patients with confounding co-morbidities such as cerebrovascular disease or when essential tremor manifests with resting tremor ${ }^{102}$ or where postural tremor predates fully developed PD.

Use of standard clinical criteria such as the UK PD Brain bank criteria is well established in research settings and can improve the accuracy of clinical diagnosis, with diagnostic specificity and sensitivity at death estimated at around 98 and $91 \% .{ }^{83-103}$ In clinical practice, strict application of these criteria will reduce the false positive rate but may reduce sensitivity, since atypical features such as autonomic dysfunction, early dementia and falls and blepharospasm are reported in pathologically confirmed PD. ${ }^{104}$ The importance of clinical experience and pattern recognition in diagnostic acumen is emphasized. ${ }^{103}$ The recent SIGN guidelines ${ }^{89}$ emphasize the poor specificity of a clinical diagnosis of PD in the early stages. Clinicians should consider this uncertainty when giving the diagnosis and planning management.

Ancillary tests including neuroimaging may play a role in supporting clinical diagnosis ${ }^{105}$ but cost-effectiveness is not yet established. Structural studies are generally unnecessary in uncomplicated PD but are helpful broadly in three situations. Firstly, they are mandatory in patients with commanding gait disorder to exclude normal pressure hydrocephalus, tumour or vascular parkinsonism. Secondly, particular patterns of brain atrophy or gliosis may help to define an atypical syndrome rather than PD. Mid-brain atrophy may suggest PSP, whilst cerebellar or brainstem atrophy or gliosis is more suggestive of MSA. The revised MSA consensus criteria as supportive features in distinguishing PD from MSA-P include atrophy on conventional MRI of the putamen, middle cerebellar peduncle, pons, or cerebellum. Reduced striatal levels of glucose metabolism assessed with PET in putamen, brainstem or cerebellum are also supportive, with 80-100\% sensitivity. ${ }^{106,107}$

Finally the presence and degree of cerebrovascular changes may indicate the contribution of vascular disease to the clinical features of parkinsonism. Vascular disease may alter the phenotype of PD in older patients. The presence of basal ganglia and/or thalamic infarcts is associated with an increased likelihood of a causal relationship.

Imaging of presynaptic dopamine transporters with beta or FP CIT SPECT scanning may help to determine whether there is underlying presynaptic dopamine depletion with a high sensitivity and specificity ${ }^{108}$ and are endorsed in recent UK guidelines. However, these techniques cannot distinguish between PD and atypical syndromes such as PSP and MSA. ${ }^{106}$ SPECT scanning may also be a sensitive early diagnostic marker for presynaptic parkinsonism versus non-parkinsonian tremor disorders such as essential tremor, as well as drug-induced parkinsonism and vascular parkinsonism. ${ }^{109}$ Presynaptic cerebrovascular lesions may cause 'punched out' areas of poor uptake on SPECT scanning and result in an abnormal scan which differs from the pattern seen in PD. For a review of dopaminergic imaging in parkinsonism, see Kemp (2005). ${ }^{110}$

Recently there has been much controversy regarding the issue of SWEDDS (scans without evidence of dopaminergic deficit). A number of clinical trials using imaging modalities, both PET and SPECT, 111,112 identified patients initially diagnosed with PD but found to have normal imaging ranging from $4 \%$ in later disease to $15 \%$ in the early stages. Although the issue remains controversial, the use of imaging as a diagnostic tool for PD has been endorsed by guideline groups (NICE and SIGN) and these patients are generally considered to have non-PD diagnosis. The most frequent mimics with a non-tremor dominant 
subtype of SWEDD are neuroleptic induced, vascular parkinsonism, neoplasm or Huntington's, while common mimics with tremor dominance appear to be dystonic tremor, essential tremor, psychogenic and Fragile $\mathrm{X}$ tremor ataxia syndrome (FXTAS). ${ }^{113}$

FXTAS is a late-onset genetic neurodegenerative disorder, predominantly affecting older males, characterized by tremor and ataxia with variable parkinsonism, progressive cognitive impairment, peripheral neuropathy and psychiatric co-morbidity. FXTAS is caused by the carriage of a premutation CGG (cytosine, guanine, guanine) repeat expansion (55-200) in the fragile X mental retardation 1 (FMR1) gene.

The importance of dystonic tremor as a possible mimic and cause of SWEDD is emphasized in a landmark paper. ${ }^{114}$ This study describes a group of patients with resting arm tremor associated with dystonia and 'soft' extrapyramidal signs such as reduced arm swing, increased limb tone and hypomimia, carrying a diagnosis of possible PD. These patients were found to have normal SPECT imaging at initial assessment and on subsequent long-term follow-up. Pointers to the diagnosis apart from the presence of dystonia are absence of true akinesia, i.e. no fatiguing on repeated movements, a pronation supination tremor of the arm, a dystonic extension of the thumb, head tremor and absence of micrographia on writing. ${ }^{114}$

Other ancillary tests such as olfactory testing, transcranial sonography, genetic testing for infrequent mimics such as Huntington's disease or spinocerebellar ataxias, and sophisticated MRI studies such as diffusion weighted MRI may be useful in discriminating PD from imitators, but require further study before they can be recommended in routine practice. ${ }^{74}$ Cardiac MIBG (metaiodobenzylguanidine) may help to distinguish PD from MSA by demonstrating sympathetic involvement in PD but not MSA. ${ }^{115}$ Acute dopaminergic challenge tests lack precision and are unhelpful in discriminating PD from atypical syndromes, particularly in early disease. ${ }^{116} \mathrm{~A}$ response to a trial of chronic levodopa therapy is helpful in supporting a diagnosis of PD, but an adequate challenge should be regarded as 1000 mg per day for at least 1 month. Some patients, particularly the elderly or those with cognitive impairment, may be unable to tolerate such doses because of significant neuropsychiatric effects or postural hypotension.

\section{Sub-groups in PD}

The clinical heterogeneity of $\mathrm{PD}$, even in the early stage, ${ }^{117}$ has supported the concept of sub-groups of $\mathrm{PD}$. More rapidly progressive disease is recognized in the elderly, ${ }^{118-120}$ often associated with early postural instability and gait difficulty, so called PIGD sub-type. Other axial features that are unresponsive to levodopa, such as freezing, dysarthria and cognitive impairment, ${ }^{121}$ may be prominent in some older patients and suggest widespread pathology outside the nigrostriatal system. Atypical parkinsonian syndromes should be considered in the differential diagnosis of such cases, ${ }^{122}$ as should overlap with other common disorders of ageing such as Alzheimer's and cerebrovascular disease. ${ }^{123}$ Older patients may have less motor fluctuation and dyskinesia despite more rapid progression. ${ }^{124}$

In contrast, the sub-type of tremor dominant $\mathrm{PD}$ is generally associated with a younger age at onset, ${ }^{125}$ a more benign clinical course and preserved mental status. ${ }^{119,120-126}$ Conflicting studies report that prominent tremor is associated with older age, ${ }^{127}$ dementia $^{128}$ and to a lesser extent rapid disease progression. ${ }^{128}$ Other data suggest few clinical differences between youngand old-onset PD, ${ }^{129}$ although muscular stiffness and sensory symptoms may be a more common presentation in younger patients. ${ }^{127}$

The variance in the literature may be partly explained by methodological differences and varying clinical populations, as well as bias in the use of retrospective study design. A recent systematic review has confirmed the cluster profiles 'old age-at-onset and rapid disease progression' and 'young age-at-onset and slow disease progression' from the majority of studies. ${ }^{130}$

A further analysis has suggested that PD sub-types can be largely characterized by the severity of non-dopaminergic features and motor complications and are likely explained by interactions between disease mechanisms, treatment, ageing and gender. ${ }^{131}$

Another recent study (PD PROMS group) has looked at the association between motor subtypes and mood. Regression models suggested an increased risk of anxiety in patients with younger age-of-onset and motor fluctuations. In contrast, depression related most strongly to axial motor symptoms. ${ }^{132}$ 
Further prospective study warrants incorporation of genetic typing and neuropathology. A recent study ${ }^{133}$ reports that a combination of Lewy- and Alzheimer-type pathologies is a robust pathological correlate of dementia in Parkinson's disease.

A quantitative assessment of Lewy pathology appears more informative than Braak $\alpha$-synuclein stages. Cortical $\beta$-amyloid and age at disease onset seem to determine the rate of dementia. ${ }^{133}$ An important clinicopathological paper demonstrates that age is inversely related to the time to development of key non-motor features or socalled 'milestones' in disease such as falls, dementia, visual hallucinations and need for residential care with younger patients having a longer period of 'benign' disease. In contrast, the advanced disease phase appears similar at all ages with a common pathological end-point and a mean end-stage disease of around five years from appearance of 'milestones'. ${ }^{134}$

\section{Conclusions}

Greater understanding of the aetiology, genetics and pathological progression of Parkinson's disease is informing our understanding of the heterogeneity of PD in clinical practice. Nevertheless, many other conditions both neurodegenerative (e.g. MSA, PSP, Alzheimer's disease) and non-neurodegenerative (e.g. cerebrovascular disease, drug-induced parkinsonism), as well as confounding co-morbidities, occur commonly in older persons and may share similar clinical features to PD. This emphasizes the importance of regular ongoing clinical follow-up by appropriately experienced movement disorder specialists in ensuring security or revision of diagnosis and optimal management. ${ }^{88,89}$ The contribution of collaborative working between geriatricians and neurologists in the UK (supported by the British Geriatrics Society Movement Disorder Section) in advancing care and research in frail PD patients has been acknowledged. ${ }^{135}$

The relentless and irreversible 'spread' and progression of pathological changes in $\mathrm{PD}$ is correlated with an increasing burden of nonmotor features in PD and presents a formidable challenge to the clinician as disease progresses. The second part of this contribution will review the pharmacological and surgical management of PD during the progressive stages of PD, with a focus on the assessment and management of non-motor features.

\section{Declaration of interests}

Dr Macphee and Dr Stewart have received honoraria or travel support from Abbott, Boeringher Ingelheim, Genus, Glaxo Smith Klein, Orion, Teva Lundbeck, UCB who manufacture anti-Parkinson's drugs, and GE who manufacture an isotope for DAT scanning.

\section{References}

1 Hely MA, Morris J, Reid WGJ, Trafficante R. Sydney multicenter study of Parkinson's disease: non-motor problems dominate at 15 years. Mov Disord 2005; 20: 190-99.

2 Stern M, Lang A, Poewe W. Toward a redefinition of Parkinson's disease. Mov Disord 2012; 27: 54-60.

3 Schrag A, Jahanshahi M, Quinn NP. What contributes to quality of life in patients with Parkinson's disease. J Neurol Neurosurg Psychiatry 2000; 69: 308-12.

4 Global Parkinson's disease Survey Steering Committee. Factors impacting on quality of life in Parkinson's disease. Mov Disord 2002; 17: 60-67.

5 Jarman B, Hurwitz B, Cook A. Effects of community based nurses specialising in Parkinson's disease on health outcome and costs: a randomised control study. BMJ 2002; 324: 1072-75.

6 MacMahon DG, Thomas S. Practical approach to quality of life in Parkinson's disease: the nurse's role. J Neurol 1998; 245 (suppl 1): S19-22.

7 Iansek R. Interdisciplinary rehabilitation in Parkinson's disease. In Stern GM (ed), Advances in Neurology, vol 80. Philadelphia: Lippincott Williams and Wilkins, 1999, pp. 555-59.

8 Mutch WJ, Dingwall-Fordyce I, Downie AW, Paterson JG, Roy SK. Parkinson's disease in a Scottish city. BMJ 1986; 292: 534-36.

9 Twelves D, Perkins K, Counsell C. Systematic review of incidence studies of Parkinson's disease: variation by age, gender and race/ethnicity. Mov Disord 2003; 18: 19-31.

10 Taylor K, Cook J, Counsell C. Heterogeneity in male to female risk for Parkinson's disease. J Neurol Neurosurg Psychiatry 2007; 78: 905-6.

11 Mehta P, Kifley A, Wang J, Rochtchina E, Mitchell P, Sue C. Population prevalence and 
incidence of Parkinson's disease in an Australian community. Intern Med J 2007; 37: 812-14.

12 Seo W, Koh S, Kim B, Yu S, Park M, Park K, Lee D. Prevalence of Parkinson's disease in Korea. J Clin Neurosci 2007; 14: 1155-57.

13 Tan L, Venketasubramanian N, Jamora R, Heng D. Incidence of Parkinson's disease in Singapore. Parkinsonism Relat Disord 2007; 13: 40-43.

14 Okubadejo N, Bower JH, Rocca WA, Maraganore DM. Parkinson's disease in Africa: a systematic review of epidemiologic and genetic studies. Mov Disord 2006; 21: 2150-256.

15 Postuma R, Wolfson C, Rajput A, Stoessl AJ, Martin W, Suchowersky O, Chouinard S, Panisset M, Jog MS, Grimes DA, Marras C, Lang AE. Is there seasonal variation in risk of Parkinson's disease? Mov Disord 2007; 22: 1097-101.

16 Chen H, Zhang S, Schwarzschild M, Hernan M, Ascherio A. Survival of Parkinson's disease patients in a large prospective cohort of male health professionals. Mov Disord 2006; 1002-7.

17 Ritz B, Ascherio A, Checkoway H, Marder KS, Nelson L, Rocca WA, Ross GW, Strickland D, Van Den Eeden SK, Gorell J. Pooled analysis of tobacco use and risk of Parkinson's disease. Arch Neurol 2007; 64: 990-97.

$18 \mathrm{Hu} \mathrm{G}$, Bidel S, Jousilahti P, Antikainen R, Tuomilehto J. Coffee and tea consumption and the risk of Parkinson's disease. Mov Disord 2007; 22: 2242-48.

19 Weisskopf M, O'Reilly E, Chen H, Schwarzschild M, Ascherio A. Plasma urate and risk of Parkinson's disease. Am J Epidemiol 2007; 166: 561-67.

20 Chen H, O'Reilly E, McCullough M, Rodriguez C, Schwarzschild M, Calle E, Thun MJ, Ascherio A. Consumption of dairy products and risk of Parkinson's disease. Am J Epidemiol 2007; 165: 998-1006.

21 Dick FD, De Palma G, Ahmadi A, Scott NW, Prescott GJ, Bennett J, Semple S, Dick S, Counsell C, Mozzoni P, Haites N, Wettinger SB, Mutti A, Otelea M, Seaton A, Söderkvist P, Felice A; Geoparkinson study group. Environmental risk factors for Parkinson's disease and parkinsonism: the Geoparkinson study. Occup Environ Med 2007; 64: 666-72.

22 Ton TG, Heckbert SR, Longstreth WT Jr, Rossing MA, Kukull WA, Franklin GM, Swanson PD, Smith-Weller T, Checkoway H. Nonsteroidal anti-inflammatory drugs and the risk of Parkinson's disease. Mov Disord 2006; 21 : 964-69.

23 Wahner A, Bronstein J, Bordelon Y, Ritz B. Nonsteroidal anti-inflammatory drugs may protect against Parkinson's disease. Neurology 2007; 69: 1836-42.

24 Wahner A, Bronstein J, Bordelon Y, Ritz B. Statin use and the risk of Parkinson disease. Neurology 2008; 70: 1418-22.

25 Sundquist K, Li X, Hemminki K. Familial risks of hospitalization for Parkinson's disease in first-degree relatives: a nationwide follow-up study from Sweden. Neurogenetics 2006; 6: 23137.

26 Kurz M, Alves G, Aarsland D, Larsen J. Familial Parkinson's disease: a community-based study. Eur J Neurol 2003; 10: 159-63.

27 Graybiel AM, Hirsch EC, Agid Y. The nigrostriatal system in Parkinson's disease. $A d v$ Neurol 1990; 53: 17-29.

28 Wichmann T. Physiology of the basal ganglia and pathophysiology of movement disorders of basal ganglia origin. In Watts RL, Koller WC (eds), Movement Disorders - Neurological Principles and Practice. New York: McGraw-Hill, 1997, pp. 87-97.

29 Gerfen CR, Engber TM, Mahan LC, Suzel Z, Chase TN, Monsma FJ Jr, Sibley DR. D1 and D2 dopamine receptor-regulated gene expression of striatonigral and striatopallidal neurons. Science 1990; 250: 1429-32.

30 Gibb WRG, Lees AJ. The relevance of the Lewy body to the pathogenesis of idiopathic Parkinson's disease. J Neurol Neurosurg Psychiatry 1988; 51: 745-52.

31 Gibb WRG, Lees AJ. Pathological clues to the cause of Parkinson's disease. In Marsden CD, Fahn S (eds), Movement Disorders. Oxford: Butterworth-Heinemann, 1994, pp. 147-66.

32 Lennox GG, Lowe JS. Dementia with Lewy bodies. In Quinn NP (ed), Baillieres Clinical Neurology: Parkinsonism. London: Bailliere Tindall, 1997, pp. 147-66.

33 Spillantini MG, Crowther RA, Jakes R, Hasegawa M, Goedert M. Alpha-Synuclein in filamentous inclusions of Lewy bodies and Lewy neurites from Parkinson's disaese and dementia with Lewy bodies. Proc Natl Acad Sci USA 1998; 95: 6469-73.

34 Lowe JS. Lewy bodies. In Calne DB (ed), Neurodegerative Diseases. Philadelphia: WB Saunders, 1994, pp. 51-69.

35 Jellinger KA. Basic mechanisms of neurodegeneration: a critical update. J Cell Mol Med 2010; 14: 457-87.

36 Harrower TP, Michell AW, Barker RA. Lewy bodies in Parkinson's disease: protectors or perpetrators? Exp Neurol 2005; 195: 1-6.

37 Gibb WRG. Functional neuropathology in Parkinson's disease. Eur Neurol 1997; 38: 21-25. 
38 Fearnley JM, Lees AJ. Aging and Parkinson's disease: substantia nigra regional selectivity. Brain 1991; 114: 2283-301.

39 Cheng H, Ulane C, Burke R. Clinical progression in Parkinson disease and the neurobiology of axons. Ann Neurol 2010; 67: 715-25.

40 Sagar HJ. Clinicopathological heterogeneity and non dopaminergic influences on behavior in Parkinson's disease. In Stern GM (ed), Advances in Neurology, vol 80. Philadelphia: Lippincott, Williams and Wilkins, 1999, pp. 409-17.

41 Gibb WRG. Neuropathology of the substantia nigra. Eur Neurol 1991; 31: 48-59.

42 Gibb WRG, Lees AJ. Anatomy, pigmentation, ventral and dorsal subpopulations of the substantia nigra, and differential cell death in Parkinson's disease. J Neurol Neurosurg Psychiatry 1991; 54: 388-96.

43 Braak H, Del Tredici K, Rub U, de Vos RA, Jansen Steur EN, Braak E. Staging of brain pathology related to sporadic Parkinson's disease. Neurobiol Aging 2003; 24: 197-211.

44 Braak H, Rub U, Jansen Steur EN, Del Tredici K, de Vos RA. Cognitive status correlates with neuropathologic stage in Parkinson disease. Neurology 2005; 64: 1404-10.

45 Djaldetti R, Lev M, Melamed E. Lesions outside the CNS in Parkinson's disease. Mov Disord 2009; 24: 793-800.

46 Dickson DW, Fujishiro H, DelleDonne A, Menke J, Ahmed Z, Klos KJ, Josephs KA, Frigerio R, Burnett M, Parisi JE, Ahlskog JE. Evidence that incidental Lewy body disease is pre-symptomatic Parkinson's disease. Acta Neuropathol 2008; 115: 437-44.

47 Morrish PK, Sawle GV, Brooks DJ. An $\left[{ }^{18} \mathrm{~F}\right]$ dopa-PET and clinical study of the rate of progression in Parkinson's disease. Brain 1996; 119: 585-91.

48 McKeith IG, Galasko D, Kosaka K, Perry EK, Dickson DW, Hansen LA, Salmon DP, Lowe J, Mirra SS, Byrne EJ, Lennox G, Quinn NP, Edwardson JA, Ince PG, Bergeron C, Burns A, Miller BL, Lovestone S, Collerton D, Jansen EN, Ballard C, de Vos RA, Wilcock GK, Jellinger KA, Perry RH. Consensus guidelines for the clinical and pathologic diagnosis of dementia with Lewy bodies (DLB): report of the consortium on DLB international workshop. Neurology 1996; 47: 1113-24.

49 McKeith I, Mintzer J, Aarsland D, Burn D, Chiu $\mathrm{H}$, Cohen-Mansfield J, Dickson D, Dubois B, Duda JE, Feldman H, Gauthier S, Halliday G, Lawlor B, Lippa C, Lopez OL, Carlos Machado J, O'Brien J, Playfer J, Reid W; International Psychogeriatric Association Expert Meeting on
DLB. Dementia with Lewy bodies. Lancet

Neurology 2004; 3: 19-28.

50 Waxman EA, Giasson B. Induction of intracellular tau aggregation is promoted by alpha-synuclein seeds and provides novel insights into the hyperphosphorylation of tau. J Neurosci 2011; 31: 7604-18.

51 Mandal P, Pettegrew J, Masliah E, Hamilton R, Mandal R. Interaction between Abeta peptide and alpha synuclein: molecular mechanisms in overlapping pathology of Alzheimer's and Parkinson's in dementia with Lewy body disease. Neurochem Res 2006; 31: 1153-62.

52 Veldman BAJ, Wijn AM, Knoers N, Praamstra P, Horstink MWIM. Genetic and environmental risk factors in Parkinson's disease. Clin Neurol Neurosurg 1998; 100: 15-26.

53 Bonifati V, Fabrizio E, Vanacore N, De Mari M, Meco G. Familial Parkinson's disease: a clinical genetic analysis. Can J Neurol Sci 1995; 22: 272-79.

54 Wood N. Genetic aspects of parkinsonism. In Quinn NP (ed), Bailliere's Clinical Neurology: Parkinsonism. London: Bailliere Tindall, 1997, pp. 37-53.

55 Piccini P, Burn DJ, Ceravolo R, Maraganore D, Brooks DJ. The role of inheritance in sporadic Parkinson's disease: evidence from a longitudinal study of dopaminergic function in twins. Ann Neurol 1999; 45: 577-82.

56 Wirdefeldt K, Gatz M, Schalling M, Pedersen NL. No evidence for heritability of Parkinson disease in Swedish twins. Neurology 2004; 63: 305-11.

57 Zimprich A. Genetics of Parkinson's disease and essential tremor. Curr Opin Neurol 2011; 24: 318-23.

58 Golbe LI, Di Lorio G, Bonavita V, Miller DC, Duvoisin RC. A large kindred with autosomal dominant Parkinson's disease. Ann Neurol 1990; 27: 276-82.

59 Polymeropoulos $\mathrm{MH}$, Lavedan C, Leroy E, Ide SE, Dehejia A, Dutra A, Pike B, Root H, Rubenstein J, Boyer R, Stenroos ES, Chandrasekharappa S, Athanassiadou A, Papapetropoulos T, Johnson WG, Lazzarini AM, Duvoisin RC, Di Iorio G, Golbe LI, Nussbaum RL. Mutation in the a-synuclein gene identified in families with Parkinson's disease. Science 1997; 276: 2045-47.

60 Zimprich A, Biskup S, Leitner P, Lichtner P, Farrer M, Lincoln S, Kachergus J, Hulihan M, Uitti RJ, Calne DB, Stoessl AJ, Pfeiffer RF, Patenge N, Carbajal IC, Vieregge P, Asmus F, Müller-Myhsok B, Dickson DW, Meitinger T, Strom TM, Wszolek ZK, Gasser T. Mutations in 
LRRK2 cause autosomal-dominant parkinsonism with pleomorphic pathology. Neuron 2004; 44: 601-7.

61 Paisán-Ruíz C, Jain S, Evans EW, Gilks WP, Simón J, van der Brug M, López de Munain A, Aparicio S, Gil AM, Khan N, Johnson J, Martinez JR, Nicholl D, Carrera IM, Pena AS, de Silva R, Lees A, Martí-Massó JF, Pérez-Tur J, Wood NW, Singleton AB. Cloning of the gene containing mutations that cause PARK8-linked Parkinson's disease. Neuron 2004; 44: 595-600.

62 Gilks WP, Abou-Sleiman PM, Gandhi S, Jain S, Singleton A, Lees AJ, Shaw K, Bhatia KP, Bonifati V, Quinn NP, Lynch J, Healy DG, Holton JL, Revesz T, Wood NW. A common LRRK2 mutation in idiopathic Parkinson's disease. Lancet 2005; 365: 415-16.

63 Healy DG, Falchi M, O'Sullivan SS, Bonifati V, Durr A, Bressman S, Brice A, Aasly J, Zabetian CP, Goldwurm S, Ferreira JJ, Tolosa E, Kay DM, Klein C, Williams DR, Marras C, Lang AE, Wszolek ZK, Berciano J, Schapira AH, Lynch T, Bhatia KP, Gasser T, Lees AJ, Wood NW; International LRRK2 Consortium. Phenotype, genotype, and worldwide genetic penetrance of LRRK2-associated Parkinson's disease: a case control study. Lancet Neurology 2008; 7: 583-90.

64 Marsden CD, Olanow CW. The causes of Parkinson's disease are being unraveled and rational neuroprotective therapy is close to reality. Ann Neurol 1998; 44: S189-96.

65 Schapira AHV. Pathogenesis of Parkinson's disease. In Quinn NP (ed), Bailliere's Clinical Neurology: Parkinsonism. London: Bailliere Tindall, 1997, pp. 15-36.

66 Dexter DT, Carter CJ, Wells FR, Javoy-Agid F, Agid Y, Lees AJ, Jenner P, Marsden CD. Basal lipid peroxidation in substantia nigra is increased in Parkinson's disease. J Neurochem 1989; 52: 381-89.

67 Sanchez-Ramos JR, Överick E, Ames BN. A marker of oxyradical-mediated DNA damage (8-hydroxy-2'deoxyguanosine) is increased in nigro-striatum of Parkinson's disease brain. Neurodegeneration 1994; 3: 197-204.

68 Schapira AH. Disease modification in Parkinson's disease. Lancet Neurol 2004; 3: 362-68.

69 Hong JS. Inflammation in the pathogenesis of Parkinson's disease: models, mechanisms and therapeutic interventions. Ann NY Acad Sci 2005; 1053: 151-52.

70 Ahlskog JE. Neuroprotective strategies in the treatment of Parkinson's disease: clinical evidence. In LeWitt PA, Oertel WH (eds), Parkinson's Disease. The treatment options. London: Martin Dunitz, 1999, pp. 93-115.
71 Angot E, Steiner J, Hansen C, Li J-Y, Brundin P. Are synucleinopathies prion-like disorders? Lancet Neurol 2010; 9: 1128-38.

72 Weintraub D, Stern M. Psychiatric complications in Parkinson's disease. Am J Geriat Psychiatry 2005; 13: 844-51.

73 Wu Y, Weidong L, Jankovic J. Preclinical markers of Parkinson's disease. Arch Neurol 2011; 68: 22-30.

74 Tolosa E, Wenning GK, Poewe WH. The diagnosis of Parkinson's disease. Lancet Neurol 2006; 5: 75-86.

75 Rajput AH. Movement Disorders and Aging. In Watts RL, Koller WC (eds), Movement Disorders: Neurological Principles and Practice. New York: McGraw Hill, 1997, pp. 673-86.

76 Bennet DA, Beckett LA, Murray AM, Shannon KM, Goetz CG, Pilgrim DM, Evans DA. Prevalence of parkinsonian signs and associated mortality in a community population of older people. N Engl J Med 1996; 334: 71-76.

77 Moghal S, Rajput AH, D’Arcy C, Rajput R. Prevalence of movement disorders in elderly community residents. Neuroepidemiology 1994; 13: $175-78$.

78 Boyle P, Wilson R, Aggarwal N, Arvanitakis Z, Kelly J, Bienias J, Bennett DA. Parkinsonian signs in subjects with mild cognitive impairment. Neurology 2005; 65: 1901-6.

79 Louis ED, Tang M-X, Mayeux R. Parkinsonian signs in older people in a community based study. Arch Neurol 2004; 61: 1273-76.

80 Bower JH, Maraganore DM, McDonnell SK, Rocca WA. Incidence and distribution of parkinsonism in Olmstead County, Minnesota 1976-1990. Neurology 1999; 52: 1214-20.

81 Toth C, Rajput M, Rajput AH. Anomalies of asymmetry of clinical signs in Parkinsonism. Mov Disord 2004; 19: 151-57.

82 Macphee GJA. Diagnosis and differential diagnosis. In Playfer JR, Hindle JV (eds), Parkinson's Disease in the Older Patient. London: Arnold, 2001, pp. 43-76.

83 Hughes AJ, Daniel SE, Lees AJ. Improved accuracy of clinical diagnosis of Lewy body Parkinson's disease. Neurology 2001; 57: 1497-99.

84 Jankovic J, Rajput AH, McDermott M, Perl DP. The evolution of diagnosis in early Parkinson disease. Arch Neurol 2000; 57: 369-72.

85 Meara J, Bhowmick BK, Hobson P. Accuracy of diagnosis in patients with presumed Parkinson's disease. Age Ageing 1999; 28: 99-103.

86 Newman E, Breen K, Patterson J, Hadley D, Grosset K, Grosset D. Accuracy of Parkinson's disease diagnosis in 610 general practice patients 
in the West of Scotland. Mov Disord 2009; 15: 2379-85.

87 Schrag A, Ben-Shlomo Y, Quinn NP. How valid is the clinical diagnosis of Parkinson's disease in the community? J Neurol Neurosurg Psychiatry 2002; 73: 529-34.

88 National Institute for Health and Clinical Excellence (NICE) Guideline 35. Parkinson's Disease. 2006.

89 Scottish Intercollegiate Guidelines Network (SIGN) Guideline 113. Diagnosis and Pharmacological Management of Parkinson's Disease. 2010.

90 Hughes AJ, Daniel SE, Blankson S, Lees AJ. A clinicopathologic study of 100 cases of Parkinson's disease. Arch Neurol 1993; 50: 140-48.

91 Quinn N. Parkinsonism - recognition and differential diagnosis. BMJ 1995; 310: 447-52.

92 Katzenschlager R, Cardozo A, Cobo M, Tolosa E, Lees AJ. Unclassifiable parkinsonism in two European tertiary referral centres for movement disorders. Mov Disord 2003; 18 : 1123-31.

93 Williams DR, de Silva R, Paviour DC, Pittman A, Watt HC, Kilford L, Holton JL, Revesz T, Lees AJ. Characteristics of two distinct clinical phenotypes in pathologically proven progressive supranuclear palsy: Richardson's syndrome and PSP - parkinsonism. Brain 2005; 128: 1247-58.

94 Louis ED, Ferriera JJ. How common is the most common adult movement disorder? Update on the worldwide prevalence of essential tremor.

Movement Disorders 2010; 25: 534-41.

95 Benito-Leon J, Louis ED. Essential tremor: emerging views of a common disorder. Nat Clin Pract Neurol 2006; 2: 666-78.

96 Brennan KC, Jurewicz E, Ford B, Pullman SL, Louis ED. Is essential tremor predominantly a kinetic or postural tremor? A clinical and electrophysiological study. Mov Disord 2002; 17: 313-16.

97 Bain P, Findley LJ, Thompson PD, Gresty MA, Rothwell J, Harding AE, Marsden CD. A study of hereditary essential tremor. Brain 1994; 117: 805-24.

98 Lou JS, Jankovic J. Essential tremor: clinical correlates in 350 patients. Neurology 1991; 41: 234-38.

99 Hubble JP, Busenbark KL, Pahwa R, Lyons K, Koller WC. Clinical expression of essential tremor: effects of gender and age. Mov Disord 1997; 12: 969-72.

100 Louis ED, Ford B, Frucht S. Factors associated with increased risk of head tremor in essential tremor: a community-based study in northern Manhattan. Mov Disord 2003; 18: 432-36.
101 Deuschl G, Bain P, Brin M, Ad Hoc Scientific Committee. Consensus Statement of the Movement Disorder Society on Tremor. Mov Disord 1998; 13: 2-23.

102 Cohen O, Pullman S, Jurewicz E, Watner D, Louis ED. Rest tremor in patients with essential tremor. Arch Neurol 2003; 60: 405-10.

103 Hughes AJ, Daniel SE, Ben-Shlomo Y, Lees AJ. The accuracy of diagnosis of parkinsonian syndromes in a specialist movement disorder service. Brain 2002; 125: 861-70.

104 Hughes AJ, Ben-Shlomo Y, Daniel SE, Lees AJ. What features improve the acuracy of clinical diagnosis in Parkinson's disease: A clinicopathologic study. Neurology 1992; 42: 1142-46.

105 Piccini P, Whone A. Functional brain imaging in the differential diagnosis of Parkinson's disease. Lancet Neurol 2004; 3: 284-90.

106 Brooks DJ. Can imaging separate Multiple System Atrophy from Parkinson's disease? Mov Disord 2012; 27: 3-5.

107 Quattrone A, Nicoletti G, Messina D, Fera F, Condino F, Pugliese P, Lanza P, Barone P, Morgante L, Zappia M, Aguglia U, Gallo O. MR imaging index for differentiation of progressive supranuclear palsy from Parkinson disease and the Parkinson variant of multiple system atrophy. Radiology 2008; 246: 214-21.

108 Benamer HTS, Patterson J, Grosset DG, The $\left[{ }^{123} \mathrm{I}\right]$-FP-CIT Study group. Accurate differentiation of parkinsonism and essential tremor using visual assessment of $\left[{ }^{123} \mathrm{I}\right]$-FP-CIT SPECT imaging: The $\left[{ }^{123} \mathrm{I}\right]$-FP-CIT Study group. Mov Disord 2000; 15: 503-10.

109 Marshall V, Grosset DG. Role of dopamine transporter imaging in routine clinical practice. Mov Disord 2003; 18: 1415-23.

110 Kemp P. Imaging the dopaminergic system in suspected parkinsonism, drug induced movement disorders, and Lewy body dementia. Nuclear Medicine Comm 2005; 26: 87-96.

111 Whone AL, Watts RL, Stoessl AJ, Davis M, Reske S, Nahmias C, Lang AE, Rascol O, Ribeiro MJ, Remy P, Poewe WH, Hauser RA, Brooks DJ; REAL-PET Study Group. Slower progression of Parkinson's disease with ropinirole versus levodopa: The REAL-PET study. Ann Neurol 2003; 54: 93-101.

112 Fahn S, Oakes D, Shoulson I, Kieburtz K, Rudolph A, Lang A, Olanow CW, Tanner C, Marek K; Parkinson Study Group. Levodopa and the progression of Parkinson's disease. N Eng J Med 2004; 351: 2498-508.

113 Bajaj N, Birchall J, Patterson J, Grosset D, Lees AJ. The accuracy of clinical diagnosis in tremulous 
parkinsonian patients: a blinded video study. J Neurol Neurosurg Psychiatry 2010; 81: 1123-28.

114 Schneider SA, Edwards MJ, Mir P, Cordivari C, Hooker J, Dickson J, Quinn N, Bhatia KP. Patients with adult-onset dystonic tremor resembling parkinsonian tremor have scans without evidence of dopaminergic deficit (SWEDDs). Mov Disord 2007; 22: 2210-15.

115 Braune $\mathrm{S}$. The role of cardiac metaiodobenzylguanadine uptake in the differential diagnosis of parkinsonian syndromes. Clin Autonomic Res 2001; 11: 351-55.

116 Bhatia K, Brooks DJ, Burn DJ, Clarke CE, Grosset DG, MacMahon DG, Playfer J, Schapira AH, Stewart D, Williams AC; Parkinson's Disease Consensus Working Group. Updated guidelines for the management of Parkinson's disease. Hosp Med 2001; 62: 456-70.

117 Lewis S, Foltynie T, Blackwell A, Robbins T, Owen A, Barker R. Heterogeneity of Parkinson's disease in the early clinical stages using a data driven approach. J Neurol Neurosurg Psychiatry 2005; 76: 343-48.

118 Diamond SG, Markham CH, Hoehn MM, McDowell FH, Muenter MD. Effect of age at onset on progression and mortality in Parkinson's disease. Neurology 1989; 39: 1190.

119 Zetusky WJ, Jankovic J, Pirozzolo FJ. The heterogeneity of Parkinson's disease: clinical and prognostic implications. Neurology 1985; 35: 522-26.

120 Goetz CG, Tanner CM, Stebbins GT, Buchman AS. Risk factors for progression in Parkinson's disease. Neurology 1988; 38: 1841-44.

121 Jankovic J, McDermott M, Carter J, Gauthier S, Goetz C, Golbe L, Huber S, Koller W, Olanow C, Shoulson I et al. Variable expression of Parkinson's disease: a baseline analysis of the DATATOP cohort. Neurology 1990; 40: 1529-34.

122 Rajput AH, Pahwa R, Pahwa P, Rajput A. Prognostic significance of the onset mode in parkinsonism. Neurology 1993; 43: 829-30.

123 Nataraj A, Rajput AH. Parkinson's disease, stroke and related epidemiology. Mov Disord 2005; 20: 1476-80.

124 Schrag A, Quinn NP, Ben-Shlomo Y. Heterogeneity of Parkinson's disease. J Neurol Neurosurg Psychiatry 2006; 77: 275-76.
125 Tanner CM, Kinori I, Goetz CG, Carvey PM, Klawans HL. Age at onset and clinical outcome in idiopathic Parkinson's disease. Neurology 1985; 35: 276.

126 Roos RAC, Jongen JCF, van der Velde EA. Clinical course of patients with idiopathic Parkinson's disease. Mov Disord 1996; 11: 236-42.

127 Friedman A. Old onset Parkinson's disease compared with young onset disease: clinical differences and similarities. Acta Neurol Scand 1994; 89: 258-61.

128 Hely MA, Morris JGL, Reid WGJ, O'Sullivan DJ, Williamson PM, Broe GA, Adena MA. Age at onset: the major determinant of outcome in Parkinson's disease. Acta Neurol Scand 1995; 92: 455-63.

129 Gibb WR, Lees AJ. A comparison of clinical and pathological features of young and old onset Parkinson's disease. Neurology 1988; 38: 1402-6.

130 van Rooden S, Heiser W, Kok J, Verbaan D, van Hilten JJ, Marinus J. The identification of Parkinson's disease subtypes using cluster analysis: A systematic review. Mov Disord 2010; 25: 969-78.

131 van Rooden SM, Colas F, Martínez-Martín P, Visser M, Verbaan D, Marinus J, Chaudhuri RK, Kok JN, van Hilten JJ. Clinical subtypes of Parkinson's disease. Mov Disord 2011; 26: 51-58.

132 Burn DJ, Landau S, Hindle JV, Samuel M, Wilson KC, Hurt CS, Brown RG; PROMS-PD Study Group. Parkinson's disease motor subtypes and mood. Mov Disord 2012; 27: 379-86.

133 Compta Y, Parkkinen L, O'Sullivan SS, Vandrovcova J, Holton JL, Collins C, Lashley T, Kallis C, Williams DR, de Silva R, Lees AJ, Revesz T. Lewy- and Alzheimer-type pathologies in Parkinson's disease dementia: which is more important? Brain 2011; 134: 1493-505.

134 Kempster PA, O’Sullivan S, Holton J, Revesz T, Lees AJ. Relationships between age and late progression of Parkinson's disease: a clinicopathological study. Brain 2010; 133: 1755-62.

135 Powell C. Frailty and Parkinson's disease: theories and clinical implications. Parkinsonism Relat Disord 2008; 14: 271-72. 